\title{
Emotions and Their Correctness Conditions: A Defense of Attitudinalism
}

\author{
Julien Deonna ${ }^{1} \cdot$ Fabrice Teroni $^{1}$ (D)
}

Received: 13 September 2021 / Accepted: 30 January 2022

(c) The Author(s) 2022

\begin{abstract}
In this paper, we contrast the different ways in which the representationalist and the attitudinalist in the theory of emotions account for the fact that emotions have evaluative correctness conditions. We argue that the attitudinalist has the resources to defend her view against recent attacks from the representationalist. To this end, we elaborate on the idea that emotional attitudes have a rich profile and explain how it supports the claim that these attitudes generate the wished-for evaluative correctness conditions. Our argument rests on the idea that emotional attitudes manifest a sensitivity to evaluative evidence and that this sensitivity secures the kind of normativity we expect of the emotions. We bring our discussion to a close by assessing whether the psychological underpinnings of this sensitivity to evaluative evidence are such as to threaten the foundation of attitudinalism: the idea that emotions do not represent values. Given the available models of how we might access values prior to emotional experience, we conclude that the attitudinalist is still in the game.
\end{abstract}

A recent debate in the philosophy of emotion opposes what we will call the representationalists (Milona, 2016; Roberts, 2003; Rossi \& Tappolet, 2019; Tappolet, 2016) and the attitudinalists (Deonna \& Teroni, 2012, 2015; Mitchell, 2019a, 2021; Müller, 2017, 2019; Mulligan, 2007). Both parties think that emotions are in some sense evaluations and that it is the task of a philosophical theory of the emotions to capture the truth in this idea, and in particular to explain how emotions are personal level evaluations. ${ }^{1}$ There is also agreement on the fact that, because they are

\footnotetext{
1 This emphasis on the personal level is not shared by all evaluative approaches. Some of them are premised on the idea that a relation of causal co-variation between values and emotions plus biological function is enough to conclude that emotions represent values (for an approach along these lines, see Prinz 2004). For reasons we won't have the time to elaborate on, it is unclear whether the debate between the
}

Fabrice Teroni

Fabrice.Teroni@unige.ch

Julien Deonna

Julien.Deonna@unige.ch

1 Department of Philosophy, University of Geneva, 2, rue de Candolle, 1211 Geneva, Switzerland 
evaluations, emotions have evaluative correctness conditions. In fear of a dog, there is a threat-related evaluation of the dog; in amusement, there is a funniness-related evaluation of a joke. The fear is correct if and only if the dog is threatening; the amusement is correct if and only if the joke is funny.

Representationalists and attitudinalists agree, moreover, that emotions, similarly to beliefs and, perhaps, perceptual states, have mind-to-world direction of fit. They contrast in this respect with desires, which according to the standard view have world-to-mind direction of fit: desires may be satisfied or frustrated, but neither correct nor incorrect (Searle, 1983; Smith, 1994). ${ }^{2}$ There is also agreement on the fact that "correctness" is meant here in the quite traditional sense it suggests. ${ }^{3}$ By this we mean, first, that for a given type of emotion, correctness is a matter of the emotion's matching a specific evaluative property (threat in fear, funniness in amusement, etc.) and not any kind of prudential or moral value: a correct fear might not match the prudential or moral landscape (D'Arms and Jacobson, 2000). Second, the fact that an emotion matches the relevant evaluative property is not to be confused with its being one that we are (most) justified in feeling (Echeverri, 2019). That is to say, both camps are keen to preserve the distinction between correctness conditions and justification conditions. If a reliable friend tells you that a distant relative just passed away, your sadness may be justified even if, in fact, the relative is still alive and well; your sadness is then incorrect. Conversely, if you trust a notoriously unreliable friend who tells you the same, your sadness may be unjustified even if, as things turn out, the relative indeed passed away; your sadness is then correct. That being said, justification does not float free of correctness (e.g., Engel, 2013; Wedgwood, 2002). A plausible view is that a justified emotion is one that the evidence accessible from the subject's perspective makes seemingly correct. Still, for any given emotion, the two properties can diverge: an emotion can be correct but unjustified, or justified but incorrect.

This is the common ground between the two camps, but representationalists and attitudinalists have very different ways of articulating these ideas. According to representationalists, the best way of understanding the idea that emotions are evaluations is in terms of the representation of evaluative properties: fear of a dog is an evaluation because it (partly) consists in the representation of the dog's being threatening; amusement at a joke is an evaluation because it (partly) consists in the representation of the joke's funniness. There are many ways of being a representationalist, but the most popular view nowadays has it that emotions are evaluations because they are experiences of the relevant evaluative properties (Milona, 2016; Roberts, 2003; Tappolet, 2016). On this view, evaluative properties are

\section{Footnote 1 (continued)}

representationalist and the attitudinalist can get a foothold if one adopts an account of emotional evaluation in subpersonal terms.

${ }^{2}$ We will have the occasion to revisit this standard view below and to ponder over some reasons to think that desires also have correctness conditions.

3 The idea of correctness and incorrectness in emotion started receiving widespread attention in the works of Brandt (1946), Brentano (1889/1969), Broad (1954), Husserl (1988), Pitcher (1965) and Scheler (1916/1973). 
experientially manifest in emotion, and this does not merely amount to attributing evaluative properties to the relevant objects, as might be the case when we make an evaluative judgment. ${ }^{4}$ Contemporary representationalists have been keen on drawing parallels with perceptual experience to convey the gist of their view: emotions make evaluative properties manifest in a way that closely parallels the way perception makes manifest, say, visual properties (for instance colors, shapes, different categories of objects, affordances, perhaps) (Milona, 2016; Tappolet, 2016; Wringe, 2014). According to representationalists, emotions have evaluative correctness conditions because they represent evaluative properties in this experiential way. It is because an episode of fear of a harmless dog represents the dog as a threat that it is incorrect. Emotions, like perceptual states, would, on this view, be (quasi) receptive faculties registering or recognizing the relevant aspects of the environment (more on this shortly).

According to the attitudinalist, by contrast, the evaluation in emotion should not be understood in representational terms. The relation between the emotion and the evaluative property is claimed to be similar to the relation between, say, belief and truth. Belief does not as such represent the truth of the proposition believed. Rather, the relation of belief to truth is a matter of the specific profile of the attitude of believing - that is, it is a matter of belief's being the attitude that consists in treating a proposition as a premise in deliberation, assenting to it when relevant, responding to evidence for or against the proposition's being the case, and so on. Similarly, on the attitudinalist picture, emotions are evaluations because they are attitudes of specific kinds. Fearing (a dog), being amused (by a joke) are specific ways of reacting to and feeling engaged vis-à-vis their objects, and it is in virtue of being such attitudes that emotions are evaluations. Note that the attitudinalist does not deny that emotions involve representation. Being afraid of a dog of course involves representing (perceptually, mnesically, imaginatively, etc.) the dog and a specific subset of its properties - this is to say that emotions involve representations through their cognitive bases (Deonna \& Teroni, 2012). In the same way, someone insisting that a belief is correct if and only if the proposition believed is true does not mean to deny that a proposition or a state of affairs is represented in belief. What the attitudinalist denies is that, in belief or in emotion, the relevant correctness conditions are due to the representation of the proposition's truth or of the dog's threatening character. Emotions are evaluations because they are the specific kinds of attitudes that they are. It is for instance because fear contains a specific way of being engaged vis-à-vis the dog that it is correct or incorrect as a function of whether the dog is a threat. As a result, the attitudinalist portrays the evaluative dimension of emotions in a way that strikingly contrasts with the representationalist picture. This evaluative dimension is not construed as being receptive, but rather derives from specific kinds of engagement towards what is represented.

\footnotetext{
${ }^{4}$ Within the representationalist camp, it is widely acknowledged that judgementalism about the emotions (to fear the dog is to judge that the dog is dangerous) faces insuperable challenges (e.g., Deigh 1994), hence we shall not discuss it in what follows.
} 
It is helpful to stress again that, according to the attitudinalist, emotional attitudes make a key contribution to correctness conditions. The attitudinalist about the emotions understands the (primary) contribution of emotional attitudes as that of providing correctness conditions, as in the case of belief. Other attitudes may not generate correctness conditions but satisfaction conditions instead. An attitudinalist sympathetic to the standard view of desire hinted at above will want to say that it because the subject is engaged with what is represented in the way characteristic of desire (being motivated to bring about a state of affairs, taking anticipatory satisfaction in its coming about, ceasing to desire once the state of affairs obtains, etc.) that desire has satisfaction conditions instead of correctness conditions.

The aim of this paper is to explore whether the representationalist and the attitudinalist are on equal footing regarding their capacity to capture the sense in which emotions have evaluative correctness conditions. It has been argued recently that the representationalist is in a much better position in this regard (Ballard, 2021; Dokic and Lemaire, 2015; Rossi \& Tappolet, 2019). The claim is that, contrary to the attitudinalist's claims, evaluative correctness conditions must originate in evaluative representation: whatever the shape of emotional attitudes, they cannot as such generate the right type of evaluative correctness conditions.

Our discussion is structured as follows. In Sect. 1, we examine the idea that correctness conditions in general exclusively derive from representation and argue that the contribution of attitudes cannot be eliminated altogether. In Sect. 2, we turn our attention to the more specific claim that evaluative correctness conditions of the kind emotions have must trace back to the contribution of evaluative representation. We argue that the final verdict on this count depends on what attitudes are, and that emotional attitudes may have the profile required to generate evaluative correctness conditions. In Sect. 3, we answer worries to the effect that attitudinal profiles cannot generate the sort of normativity we are after when we think of emotions as evaluations. Finally, in Sect. 4, we assess the consequences for attitudinalism of the fact that the needed attitudinal profiles presuppose that emotions are reactions to representations of value.

\section{Doing Without Attitudes?}

The first idea we shall explore is that, quite independently of any view we might have about the emotions, mental representation just is representation of correctness or satisfaction conditions (Searle, 1983; Siegel, 2010). The ideas of correctness and satisfaction conditions are ideas of two respective standards to which mental states can be answerable - and it is indeed very natural to think that mental states are answerable to such standards because they represent things as such-and-such. A belief that there are beers in the fridge is correct when there are beers in the fridge, because that is where the belief represents the beers to be. A desire to drink a beer is satisfied when one drinks a beer, because it represents the obtaining of one's drinking of the beer. The representationalist would have the upper hand simply because of the essential relation between representation and correctness or satisfaction 
conditions - a relation so tight that it leaves no room for the attitudinalist alternative. Is this along the right track?

The main worry with this idea is that no enrichment of the candidate representation is apt to generate the relevant correctness or satisfaction conditions. Consider first representation of truth in belief. You may represent the truth of a proposition when you imagine or desire it, but this certainly does not amount to believing it. ${ }^{5}$ If you imagine or desire the truth of a proposition, your mental state will not be correct if and only if the representation is true. Consider now the representation of the obtaining of a proposition in desire. You can represent the obtaining of a given proposition, or even a state of affairs as a goal of yours, without desiring it. And if you do not desire the proposition, your mental state will not have as its satisfaction conditions the obtaining of the proposition. In both cases, enriching what is represented does not seem the right direction to take. This is why there is a long tradition of accounting for correctness or satisfaction conditions by appealing to representation and attitude. The fact that a mental state is correct if and only if $\mathrm{p}$ is true or if and only if p obtains turns out to be the joint contribution of what is represented and a certain attitude towards what is represented-believing or desiring, as the case may be. These attitudes as such contribute to correctness or satisfaction conditions: not because they constitute an additional layer of representation, but because they are the very attitudes that they are. ${ }^{6}$

Why is it that, when you believe that $\mathrm{p}$, the correctness conditions of your belief are its being true that $p$ ? And that, when you desire that $p$, the satisfaction conditions are its coming about that $\mathrm{p}$ ? The natural answer is that these mental states have these correctness conditions because of their attitudinal profile. ${ }^{7}$ In the case of belief, this profile involves being engaged in a specific way with a proposition (treating it as a premise in deliberation, assenting to it when relevant, responding to evidence for or against its truth, etc.) (Price, 1969, p 254ff). It is because one has this attitude toward the proposition that $\mathrm{p}$ that one's mental state is correct if and only if $\mathrm{p}$ is true. Things are similar for the satisfaction conditions of desire. The desire that $p$ has these satisfaction conditions because of the attitudinal profile of desiring (being motivated to make a state of affairs come about, taking anticipatory satisfaction in it, ceasing to desire the state of affairs when it obtains, etc.). It is because one has this

\footnotetext{
5 It goes without saying that the way we use "representation" does not imply representing something as true, or the argument here would not get off the ground. This terminological choice has no impact on what follows.

6 There are additional benefits that allegedly accrue to an understanding of correctness conditions as the joint upshot of attitudes and contents but that will not be explored here. For discussion, see e.g. Deonna and Teroni (2012) and Recanati (2007).

7 Starting with Broad (1930) and Ewing (1947), many have considered that correctness for mental states is a primitive notion. More recently, Wedgwood (2002who recruits a view Roberts) defends this "primitivist" view in relation to belief and truth, while McHugh and Way (2016) adopt it across the board. While some forms of attitudinalism may take this route, in this paper we build on Deonna and Teroni (2012) and Sharadin (2016) to argue that we can shed light on the correctness conditions of various mental states by looking at the relevant attitudinal profiles. Observe in passing that this strategy has the consequence that the correctness conditions of beliefs and desires are hostage to the profile these attitudes (typically) have and so to empirical adjustment or revision.
} 
attitude toward the proposition that $\mathrm{p}$ that one's mental state is satisfied if and only if $\mathrm{p}$ obtains.

So, the attitudinalist has it that in belief and desire there are in each case two distinct factors contributing to the correctness or satisfaction conditions of the relevant state: there is the contribution of the proposition represented and the contribution of the attitude, i.e. the way one is engaged toward the proposition in question. The key claim of the attitudinalist about emotions is that the sense in which emotions are evaluations is to be modelled in just the same kind of way: emotions are evaluations because they are the very attitudes they are, and not because they represent the relevant values. In the same way as it is wrong-headed to enrich propositional representation to capture the truth-related correctness conditions of belief or the goal related satisfaction conditions of desire, it is wrong-headed to try to capture the evaluative correctness conditions of emotions by claiming that they represent values. ${ }^{8}$

What to make of this? The representationalist may be moved by the considerations above and accept that all is not a matter of representation, and that correctness conditions are the joint upshot of a representation and an attitude. Given the prevalence of the perceptual model in contemporary representationalism, they are likely to recruit the attitude characteristic of perception and connect it to an evaluative representation. For the sake of argument, let us suppose that the attitude characteristic of perception is a matter of the relevant representation "seeming true" or "seeming present" (Roberts, 2003; Döring, 2007, for a general discussion of seemings see Tucker, 2013). The representationalist would thus claim that the evaluative correctness conditions of emotions are the joint upshot of this non-evaluative attitude and an evaluative representation. For the representationalist, emotions are evaluations because they contain representations of values, and not because of the attitude(s) that accompany these representations (for this attitude is closely analogous to nonevaluative perception). This is in sharp contrast with the central attitudinalist claim, that the evaluative aspect of emotions' correctness conditions is generated by the distinctive attitudinal character of the respective emotions.

How should we proceed from here? The key issue is whether we should go with the attitudinalist and claim that the contribution of emotional attitudes to correctness conditions is advantageously extended to the relations of emotions to values. This issue will be taken up in Sect. 2. Before we come to that, let us say a few words about how the basic disagreement between the attitudinalist and the representationalist about emotions does not only revolve around correctness conditions, but is also anchored in different approaches to emotional phenomenology.

On the attitudinalist approach, the phenomenology of emotion is primarily the phenomenology of a reaction to what is represented. As the case may be, it is the phenomenology of, for instance, a fear reaction, an anger reaction, or an amusement

\footnotetext{
${ }^{8}$ In doing so, the attitudinalist does not deny that there are many distinctions between emotional experiences and paradigmatic propositional attitudes such as belief and desires. According to the attitudinalist, the fact that (many) emotions may have nonpropositional content does not threaten the basic contention that a satisfactory approach to the emotions must refer to (evaluative) attitudes. The important question regarding how the attitudinalist key claim relates to the understanding of emotions as experiences will be taken up shortly.
} 
reaction to what is represented (Müller, 2018; Mulligan, 2010; Zamuner, 2015). You are insulted and get angry: your anger feels like a reaction to the insult. Someone tells you a joke and you are amused by it: your amusement feels like a reaction to the joke. For the attitudinalist, emotions are ways of reacting to what we represent, and this chimes well with how they are experienced at the personal level. In so doing, the attitudinalist is keen to emphasize that emotional experience is not transparent (Harman, 1990). While in emotion your attention is typically focused on what is represented, it is easy to switch attention to the emotional reaction itself (Deonna \& Teroni, 2012; Mitchell, 2019b). Switching attention in this way typically makes the reaction to the representation manifest, as opposed to what you are reacting to. This is in sharp contrast with the transparency characteristic of perceptual experience. ${ }^{9}$ As a result, the attitudinalist is keen on saying that emotions are evaluations (primarily) because they consist in a subject's reaction to what is represented-a reaction that is correct if and only if what is represented exemplifies the relevant value. ${ }^{10}$

Things are different on the representationalist approach, in which the phenomenology of emotion is a phenomenology of registering or being receptive to the presence of a value. As the case may be, it is the phenomenology of a receptivity to threat (fear), offense (anger) or funniness (amusement). The sense of "registering" or "being receptive" at issue is modelled on what happens in typical cases of perception (Pelser, 2014; Tappolet, 2016): in the same way as one is, say, visually struck by the presence of a red stain on the wall, one is, in fear, struck by the presence of a threat. ${ }^{11}$ The phenomenology of emotional experience is the phenomenology of a given value being made manifest to one, and not the phenomenology of a reaction to what is represented.

We have laid out two divergent ways of understanding the sense in which emotions are evaluations. According to the representationalist approach, emotions are evaluations because they represent values. Whatever emotional attitudes are for the representationalist, they are not what generates evaluative correctness conditions. This is where the attitudinalist disagrees. For her, there are advantages in locating the sense in which emotions are evaluations at the level of the attitude. What remains to be seen is what exactly these advantages are. To see what they might be, we should see just what the attitudinalist has to say about the nature of emotional attitudes.

\footnotetext{
9 This is not to say that one is always aware of the same sort of thing when one turns one's attention "inwards", so to say (Lambie and Marcel 2002). The attitudinalist simply insists on the fact that the idea of a reaction to what one represents is anchored in the non-transparency of emotional experience.

${ }^{10}$ We shall have the opportunity to elaborate on the nature of these reactions in Sect. 2.

11 In this paper, we can be quite inclusive as to the sorts of perceptual phenomena that the representationalist appeals to. The idea that, in emotion experience, the subject is receptive to the evaluative property is sufficient to capture the spectrum of views that interest us-from the claim that emotions are simple perceptions of values (Tappolet 2016) to the claim that they involve seeing an object as having the relevant values (Pelser 2014; Roberts 2003). We shall have the opportunity of revisiting this issue when we consider our access to value prior to the emotions in Sect. 4.
} 


\section{What Are Emotional Attitudes?}

Representationalists and attitudinalists agree that emotions are evaluations, i.e. that they have evaluative correctness conditions. The fact that emotions have evaluative correctness conditions, all agree, must trace back to some evaluative aspect of the emotions: either they represent a value, or they are evaluative attitudes. As we have seen, the representationalist need not deny that there is an attitude involved in emotion: what he is opposed to is the idea that we can capture the evaluative aspect of correctness conditions in attitudinal terms. For the representationalist, to speak of evaluation is to speak of evaluative representation.

It is true that the idea of a mental state that is evaluative because it contains an evaluative attitude, and not because it contains the representation of a value, is at first sight not easy to make out. While it makes sense to appeal to attitudes so as to distinguish mental states with correctness conditions (belief) from mental states with satisfaction conditions (desire), or to distinguish belief from perception, extending the attitudinalist strategy further may seem farfetched (Langland-Hassan 2015). For example, everyone should agree that the prospects for understanding how a mental state can be correct if and only if the temperature is $32^{\circ} \mathrm{C}$, or if and only if its object has seven sides, in terms of the contribution of attitude are dim. Such correctness conditions cannot be captured in attitudinal terms; they clearly presuppose the representation of a given temperature or number of sides. We might have the intuition that the same is true of all evaluative properties: that if they enter into the correctness conditions of a mental state, this must be because they are represented. So, the key question is whether the attitudinalist has something to say about the profile of emotional attitudes that could persuade us that they indeed qualify as evaluative attitudes.

Recall that the attitudinalist about the relation of belief to truth has it that it because the attitude of believing has a specific profile (treating a proposition as a premise in deliberation, assenting to it when relevant, responding to evidence for or against its truth, etc.) that it is correct if and only if what is represented is true. Similarly, the attitudinalist about the relation of desire to satisfaction conditions has it that it is because the attitude of desiring has a specific profile (i.e. being motivated to make a state of affairs come about, taking anticipatory satisfaction in it, ceasing to desire the state of affairs when it obtains, etc.) that it is satisfied if and only if what is represented obtains. The attitudinalist with respect to the relation between a type of emotion and its having a given value in its correctness conditions faces the challenge of saying something about the specific emotional attitudes that is sufficiently illuminating to convince us that we should understand in this way how evaluative correctness conditions are generated.

So, what can we say about emotional attitudes? The attitudinalist insists that the most illuminating thing to say about emotional attitudes in general is that they are different ways of reacting to and engaging with what is represented (Deonna \& Teroni, 2012; Müller, 2017, 2018; Mulligan, 2007; Naar, 2020).

The attitudinalist project can be more or less ambitious. The most modest attitudinalist project would appeal to just one emotional attitude: "emoting" would always 
consist in "acknowledging" the represented object or situation to be of this or that value (Müller, 2017). A slightly less modest attitudinalist project would appeal to two distinct attitudes, say one of rejecting and one of embracing, so that the attitudinalist strategy only accounts for the emotions' polarity (Feldman, 2004; Mitchell, 2019a). Here, the contribution of emotional attitudes to correctness conditions would be limited to the fact that the evaluative correctness conditions proceed in positive or in negative evaluative terms. The more fine-grained evaluative distinctions, which are reflected in our ordinary emotion concepts (the fact that anger relates to offense, disgust to the disgusting, etc.) would be explained in terms of evaluative representation. At the other end of the spectrum, a very ambitious attitudinalist project would try to capture in attitudinal terms all fine-grained evaluative distinctions. For instance, the distinctions between anger, hatred, contempt, indignation and resentment would be explained by the existence of distinct and sufficiently fine-grained emotional attitudes, with evaluative representation playing no essential role.

In our opinion, the attitudinalist does best to opt for a middle-ground project: there are in fact a fair number of ways of emotionally engaging with the environment, from which distinct evaluative correctness conditions are generated. The hope here is that distinct types of attitudes partition the domain of value into broad families of values, but that the more fine-grained distinctions within these families (and the resulting distinctions we make between emotion types) come from elsewhere. For this middle-ground project to succeed, the attitudinalist must at the very least convince us that the attitudes in, say, anger, fear and disgust are sufficiently rich and distinctive to constitute distinct evaluative attitudes (Deonna \& Teroni, 2012; Frijda, 2007). Otherwise, there is no hope of deriving offense-, threat- or disgustingnessrelated correctness conditions out of them. The best strategy to assess the prospects of this project is to explore how attitudes are manifest at the personal level. It is true that we can characterize anger, fear and disgust in very abstract terms as all "rejecting" the relevant objects. Still, is this how they actually make themselves manifest? Consider some examples.

Take a subject reacting to an insult. His anger is a reaction to this insult-but what kind of reaction is it? The reaction in anger is an ongoing engagement with the insult or the offender that takes the shape of active hostility: the subject's attention is focused on the insult and his cognitive resources are recruited to deal with it in this way. The idea is to appeal to this attitude to explain anger's offense-related correctness conditions. The more fine-grained evaluative distinctions within this family of values (the outrageous, the irritating, the infuriating, the unjust, etc.) are not due to the presence of as many more fine-grained attitudes, but to other factors. ${ }^{12}$ Consider now someone reacting with fear to the presence of a nearby predator. His fear is a reaction to the predator. What kind of reaction? In fear, the reaction takes the shape of an ongoing engagement with the proximity of the predator so as to avoid it: the

\footnotetext{
12 In the literature, we find different models of how more fine-grained individuation of emotion types obtains, for instance through cognitive calibration (e.g., Prinz, 2004) or conceptual labeling (Barrett, 2005).
} 
subject's attention is focused on the predator and his cognitive resources are channeled so as to avoid it. Here, the attitude generates threat-related correctness conditions. Consider next someone reacting with disgust to the presence of rotting meat. This episode of disgust is a reaction to the meat. What kind of reaction? In disgust, it takes the shape of an ongoing engagement geared towards avoiding sensory contact with the object: the subject's attention is recruited to prevent all bodily contact with it. Disgust contrasts sharply with our last example, someone admiring a landscape. Admiration is here a reaction to the landscape. This ongoing engagement with the landscape takes the shape of an active, embracing and expanding exploration of it - attention is focused on the landscape and the subject's cognitive resources are recruited for this distinctive type of exploration. Here, the attitude generates admirability-related correctness conditions.

What comes out of these examples is that an emotion is a reaction to the relevant object that takes the shape of distinct types of ongoing attentional engagement with it. The idea of the middle-ground attitudinalist project is that there are a sufficient number of such engagements to partition the evaluative domain in a way that corresponds intuitively to the major families of emotions. ${ }^{13}$

If we are convinced that this is a live option, the attitudinalist may still face trouble from another direction (Ballard, 2021; Tappolet 2022; Smith, 2014). Even if the ongoing engagements in different emotions are distinct, they must still exhibit sufficient flexibility to accommodate the fact that the actual behaviors elicited by distinct emotions in different circumstances may be very similar if not identical. In fear, for instance, the "avoidance engagement" may lead one to flee, freeze or destroy the object - this last course of action being very close to what typically happens in anger. The attitudinalist must certainly make room for this flexibility in how emotions generate actions - but can she do so while hanging on to the idea that these different emotions involve different ways of being engaged with the object? How can the attitudinalist account for the fact that the engagement at the heart of a given emotion may translate in specific circumstances into behavior very similar to that typically generated by the engagement that characterizes another emotion, as when hostility towards the object is elicited by fear? One attractive option is to insist that, in an episode of fear, what organizes the subject's conscious experience is the ongoing avoidance engagement. Within it, the opportunity for hostility, as opposed to the felt inclination to flee, is experienced as a means (of last resort) to the endavoidance-that is constitutive of fear. By contrast, in anger, hostility-as opposed to, say, turning the other cheek so as to later catch one's enemy off-guard-is what organizes the subject's engagement with the object. In a nutshell, the idea is that by focusing on what happens through time, we can appreciate how identical courses of action can originate, through the means-end structure we have just drawn attention to, from distinct ongoing emotional attitudes. ${ }^{14}$

\footnotetext{
13 The emphasis on diachronic attentional engagement is found in Hernandez (2020) and Ombrato and Phillips (2020).

${ }^{14}$ The middle-ground strategy that we have just laid out-which emphasizes felt ongoing engagement and the means-end structure-may mitigate Ballard's (2021) skepticism regarding the possibility of generating distinct correctness conditions via distinct attitude profiles.
} 
To recap: according to the attitudinalist, the primary sense in which emotions are evaluations is located in their being ways of engaging with objects, and it is their distinct attitudinal profiles that generate distinct correctness conditions for different emotion types. Now, even if these various attitudinal profiles indeed feature prominently in emotions, we may still think that we are not yet where the attitudinalist wants us to be, namely anchoring evaluative correctness conditions in these attitudinal profiles.

\section{How to Derive Normativity From Attitudinal Profiles?}

Suppose that the attitudinalist succeeds in getting her project off the ground. There is the lingering suspicion that she cannot find in emotional attitudes understood along the foregoing lines something that generates evaluative correctness conditions. It is not easy to pin down a general argument supporting this suspicion, but here is a line of thought that will resonate with many. The sorts of attitudes we just mentioned (avoidance engagement, hostile engagement etc.) are no more than ways of being engaged with an object. They surely have a "psychological reality", but on the face of it they very much look like ways of being motivated. If so, isn't it more natural to think of them on the model of desire, i.e. as contributing satisfaction conditions as opposed to correctness conditions (e.g., Scarantino, 2014)?

We should tread carefully here, since the manner in which correctness conditions are anchored in psychological attitudes is complex. Consider belief, the paradigmatic mental state with correctness conditions, and think of it as having only a "psychological reality": suppose it just happens to us, without manifesting any kind of sensitivity to evidence, and consists merely in treating a proposition as a settled starting point in deliberation and action. Would there then be any hope in arguing that this attitude is correct if and only if the proposition believed is true?We might insist that there would indeed be no hope and that the transition from characterizing an attitude as "treating the proposition as a settled starting point" to "treating the proposition as true" is something that has to be gained in terms of the specific profile of the attitude. In fact belief has the needed profile since it displays the required sensitivity to evidence for or against the believed proposition. This is why its psychological profile is apt to generate truth-related correctness conditions.

In light of what we have said up to here, things look very different for desire, the paradigmatic mental state with satisfaction conditions. The picture of desire we have implicitly endorsed makes it into an attitude that occurs as a "brute psychological fact", without displaying any kind of responsiveness to, say, what is worthy of pursuit. One's desire to walk in the forest just is a psychological fact about one, which pulls one in the direction of the forest. This "pull" may be satisfied or not, but there is no sense in which it is correct or incorrect. Is this a faithful depiction of the attitude of desiring? Perhaps not. A long philosophical tradition going back at least to Aristotle insists on the idea that desires have correctness as well as satisfaction conditions, where the correctness conditions refer to the goodness of what is desired (e.g., Oddie, 2005) or to whether the desired proposition ought to be the case (e.g., Lauria, 2017). One phenomenon that this tradition emphasizes is the 
evidence-sensitivity of (most) desires and, consequently, how difficult it is to model our understanding of all desires on mere patterns of motivation that the subject herself cannot grasp as being oriented towards the promotion of what she perceives as good. This is a popular lesson of Quinn's (1993) infamous "Radio man", who cannot help but switch on all radio devices in his vicinity. Such an individual, many have thought, falls short of having genuine desires, as his motivations do not form in response to the (real or apparent) goodness of their objects.

What is important for us here is that an attitudinalist who wants to argue along these lines for the existence of correctness conditions for desire can harness two aspects of this emerging and richer attitudinal profile. Yes, desire is a form of pursuing and promoting what is represented. But this form of pursuit and promotion is sensitive to whether or not what is represented is good and to how, for example, it compares in this respect to other aims. This, the attitudinalist argues, is enough for desire to be assessable for correctness. And observe that, being an attitudinalist, she insists that this contribution to correctness conditions traces back to the attitude of desiring, and so is independent of the representation of the object one desires "under the guise of the good", or as something that ought to happen.

Whether or not this approach to desire is sustainable, we now have two examples of the sort of attitudinal profile needed to generate correctness conditions from attitudes. Do the forms of engagement characteristic of the emotions manifest the needed forms of evidence sensitivity?

The way we introduced the profile of emotional attitudes may have fostered the idea that they align with purely motivational approaches to desire. Consider anger. Merely displaying hostile behavior, one could argue, does not count as holding an evaluative attitude towards the relevant objects. There is a gap between the purely psychological fact of being hostile and the treating of an object as an offense (the latter being correct if and only if there is an offense). This gap parallels the one, in the case of belief, between taking something as a settled starting point and taking it as true. In the case of belief, this gap is crossed by means of the sensitivity to evidence displayed by the attitude of believing. We may think that things are no different in the case of anger (and emotional attitudes more generally): it is only if the attitude has a specific form of sensitivity to evidence that it qualifies as treating an object as an offense (and, more generally, treating it as having a (dis)value).

What are the prospects for saying that the attitude in anger displays a form of sensitivity to evidence apt to bridge this gap? These prospects can be assessed only in light of empirical data. It seems to us that the data in the area are in fact easier to come by than in the case of desire and they support the view that emotions are distinctively sensitive to evidence for or against the object's having the relevant evaluative property, for instance being offensive. ${ }^{15}$ It is important to emphasize that the attitudinalist is in this respect hostage to the underlying psychological facts. Suppose that cross-cultural data showed that the sorts of considerations that elicit

\footnotetext{
15 See e.g., Scherer, Mikula and Athenstaedt (1998). More generally, the idea that emotions are sensitive to evaluative evidence is for example at the heart of the very influential appraisal theory of the emotions, on which see and Moors et al. (2013).
} 
hostile attitudes are highly variable: in some cultural contexts, the attitude is exclusively elicited by strategic considerations, in others, by moral considerations, in a very small subset, by something like offense-related considerations and in still other contexts indifferently by the combination of these different sorts of considerations. In that case, the attitude would turn out to be too plastic to do the job it is supposed to do within an attitudinalist framework. This is true, but observe that, if the psychological facts were as we just sketched, it would be bad news for anyone thinking that correctness conditions are the joint upshot of a content and an (erratic, as it turns out) attitude.

Let us assume that the empirical findings are favourable to the attitudinalist. If so, the fact that emotions respond to evidence in this way means that the gap between the psychological facts and evaluative correctness conditions can be bridged. Before ending this section, though, let's consider a worry that this way of presenting the attitudinalist claim may foster. If the evidence-sensitivity of emotional attitudes is key to the attitudinalist strategy, aren't Rossi and Tappolet (2019) right in claiming that this betrays a confusion between justification and correctness, a confusion against which we warned at the very beginning of the present discussion?

This would be too quick. Take belief again. An attitudinalist about the relation between belief and truth maintains that believing a proposition is correct if and only if the believed proposition is true (partly) because believing is an attitude that displays a form of sensitivity to evidence. Her idea is not to say that there is nothing to truth but evidence-sensitivity. It is rather that truth-whether or not one subscribes to a correspondence theory of truth-is part of the correctness conditions of belief because belief has a given attitudinal profile, not because truth is represented. The situation is exactly the same with the attitudinalist who insists that the attitude of being angry is correct if and only if what is represented is offensive (partly) in virtue of this attitude being sensitive to evidence for or against the represented situation being offensive.

From the attitudinalist point of view, there is a principled reason for this insistence on sensitivity to evidence. We have seen that correctness conditions are the joint upshot of representation and attitude. If so, then the contribution of the attitude to correctness conditions is a function of the nature of the attitude-and there are several distinct types of these. One especially important distinction in the present context is the distinction between reactive and non-reactive attitudes (Müller, 2019; Mulligan, 2007; Zamuner, 2015). The attitude of perceiving, say, is a non-reactive attitude since one does not perceive in light of or on the basis of evidence. By contrast, believing and emoting are paradigmatic reactive attitudes since we believe or emote on the basis of evidence. If mental states get their truth- or value-related correctness conditions from the distinct attitudes they are, then it stands to reason that this is something that we should at least partly elucidate in terms of the sensitivity to evidence characteristic of these attitudes. Insisting on sensitivity to evidence does not mean that the attitudinalist overlooks the distinction between evidence and correctness-she simply implements for reactive attitudes the idea that they contribute to correctness conditions in virtue of what they are. 


\section{Reactions to What?}

Now for the elephant in the room. Having insisted that emotions are evaluative attitudes only if they are sensitive to evaluative evidence, the attitudinalist must admit that she is in an uncomfortable position. The selling point of her approach is that emotions qualify as evaluations not in virtue of representing value, but in virtue of being the attitudes they are. If the characterization of the relevant attitudes turns out to make reference to value representation, which is surely the only way to make sense of a sensitivity to evaluative evidence, doesn't that mean that the representationalist wins the day?

As we have reconstructed it, the debate between the representationalist and the attitudinalist concerns the sense in which emotions qualify as evaluations. We have seen that, according to the attitudinalist, emotions qualify as evaluations in virtue of being attitudes. We have considered several reasons for thinking this idea misguided and have found them inconclusive. So, at this stage, the contrast with the representationalist stays: the representationalist claims that emotions are evaluative attitudes in virtue of representing value, which the attitudinalist denies. The attitudinalist cannot deny, however, that the admission that emotions are reactions to evaluative evidence has the following two consequences. First, values must be represented and, second, this value representation is prior to the emotional reaction. ${ }^{16}$ This is to say that, at the very least, the attitudinalist must admit that her emotional attitudes are not autonomous from value representation. The question now is the significance of this admission for the attitudinalist program. ${ }^{17}$

In the context of the debate with the representationalist, the first thing to observe is that one of the driving intuitions behind the representational approach is out of the attitudinalist's reach. We have in mind the idea that emotions end the quest for the justification of the evaluative beliefs based on them in just the same way as perceptual experiences end the quest for the justification of perceptual beliefs (Döring, 2007; Pelser, 2014; Tappolet, 2016). Clearly, if emotions are reactions to evaluative evidence, then in so far as they play a justificatory role ${ }^{18}$, this must consist in their transmitting justification from this pre-emotionally available evidence rather than in ending the quest for justification (Brady, 2013; Deonna \& Teroni, 2012; Harrison, 2020). However, the intuition that emotions must play the latter role is far from

\footnotetext{
${ }^{16}$ Mitchell denies that the second consequence follows (2019a, 2021, see also Poellner 2016). According to him, once we understand emotions as felt valenced attitudes, there is no obstacle to conceive of them both as reactions to values and as representations of these same values. Engagement with this sophisticated view must await another occasion.

17 Ballard's (2021) argument to the effect that attitudinalism cannot do without value representation is in our opinion not sufficiently attentive to this issue of autonomy. The fact that the attitudinalist can and should acknowledge that value representation is prior to emotional reactions means that the presence of value representation as such does not threaten its prospects.

18 This is not to say that emotions cannot play other epistemic roles. In particular, they may play key roles in our understanding of the evaluative domain. On this issue, see Deonna and Teroni (2012, pp 122-124, 2021).
} 
widely shared, and the fate of attitudinalism is not settled by whether or not it can accommodate it. ${ }^{19}$

The significance of the admission that emotions are not autonomous from value representation depends on what it means to appeal to a pre-emotional source of evaluative information (Deonna \& Teroni, 2012: chap. 8; Mitchell, 2019c; Müller, 2019: chap.5) and whether it threatens any motivation for attitudinalism. To assess its significance, we will briefly explore three models of this pre-emotional source of evaluative information: the conceptual model, the common look model and the simple model. The aim here is not to provide definitive reasons to favour one of these models, but rather to get a sense of the costs and benefits that accrue to them.

The conceptual model is perhaps the first to come to mind: it has it that the preemotional source of evaluative information consists in aspectual perception or perceptual recognition under an evaluative guise. An episode of anger, for instance, would presuppose that the subject recognizes the relevant gesture or remark as offensive. All emotions would presuppose some such act of recognition under an evaluative guise. The hallmark of this first model is that pre-emotional value representation consists in deploying the relevant conceptual capacity: having an emotion is not autonomous because it presupposes that the subject recognizes that an object falls under the relevant concept. ${ }^{20}$

The first thing to say is that any theory should admit that, for creatures like us, many emotion episodes do indeed answer to the conceptual model: we often recognize an object or situation confronting us as instantiating the relevant value before emotionally reacting to it. The question is rather whether we have to think of every instance of emotion on this model. Perhaps not, for this would imply that it is impossible to experience an emotion without mastering the relevant evaluative concept. This is a problem insofar as many think that subjects deprived of these evaluative concepts - some non-human animals and infants-do react emotionally to their environment. ${ }^{21}$ So, if admitting that emotions are not autonomous sources of evaluative representation meant endorsing the conceptual model, this would be a substantial liability of the attitudinalist approach.

The common look model alleviates this worry. Recall how the representationalist about the emotions typically conceives of them as experiences of evaluative properties. This is a matter of the subject being receptive to the presence of the value in something like the way one is visually receptive to the presence of a colour, say. Why not recast this idea and make it into an account of pre-emotional value representation? The idea here may be that, while very diverse states of affairs can be offensive, they manifest their evaluative unity thanks to their having a common "phenomenological profile" or "look"; it is through this common look that we become pre-emotionally aware of offensiveness. Someone defending this view may

\footnotetext{
19 Dokic and Lemaire (2015) premise their whole discussion of the attitudinal view on the wrongheaded idea that all parties in the debate should accommodate this intuition.

${ }^{20}$ Müller (2019), who recruits a view Roberts (2003) initially developed about the emotions themselves, defends the idea that aspectual perception of reasons is neither sensory nor conceptual. Therefore, his view may be assimilated to the common look or to the simple view.

${ }^{21}$ For this traditional worry, see Deigh (1994).
} 
recommend it by insisting that we are just facing one case of the richness characteristic of many perceptual experiences (on rich perception, see e.g., Siegel, 2010).

However, having taken this road, we now need to convince ourselves that we are receptive to offense thanks to the existence of a sensory impression that is common to all offensive objects or states of affairs. If we fail in this, we might try to defend the common look model by steering away from the traditional sensory modalities. There would be a non-sensory phenomenological profile common to all pre-emotional representations of a given value, which would explain why the emotion is elicited (Bengson, 2015; Massin, 2019; Mulligan, 2010). This may be reminiscent of the kind of intuitionism we are accustomed to in metaethics (e.g., Huemer, 2005).

From this coarse description of these variants of the common look model, it does not seem particularly promising (Deonna \& Teroni, 2012). Still, the worries raised by the conceptual model provide a motivation to explore it further (Ballard, 2020). If the common look model is viable, then it may provide indirect additional reasons for favouring attitudinalism about the emotions. Indeed, representationalism may be thought to be tailored to account for the nature of this pre-emotional experiential route to values rather than for the sense in which emotions themselves are evaluations. In turn, this provides the motivation to explain differently the evaluative nature of emotions and, more specifically, to explore the nature of emotional attitudes.

The simple model takes the middle route. Its point of departure is the thought that objects and states of affairs are valuable in virtue of their natural properties (e.g., Foot, 2001; Thomson, 1997). The model has it that, for pre-emotional representation of value to take place, it is enough that the subject be aware of a constellation of natural properties that, in the circumstances, constitutes an instance of a given value (Deonna \& Teroni, 2012, 2021; Echeverri, 2019; see also Setiya, 2012). In the case of anger, being aware of someone's stepping voluntarily on one's feet, say, would in specific circumstances be a case of pre-emotionally representing offense. Why? Because these properties are partly constitutive of an offense. Someone sympathetic to the simple model need not of course claim that there is no other, more demanding, form of pre-emotional value representation. He simply insists that the simple model applies to many basic cases, which are not derivative of the more demanding ones (Deigh, 1994). As compared to the two previous models, the simple model tries to do a lot with a deflationary understanding of pre-emotional value representation: neither concept deployments nor potentially problematic "common evaluative looks" are required. It seeks in that way to circumvent the worries raised in the foregoing.

Not surprisingly, these benefits turn easily into shortcomings. The advocate of the simple model must show that being aware of the relevant constellation of natural properties is indeed sufficient for the resulting emotion to count as a reaction to the object's value. While this comes for free in the other models, the challenge for the simple model is substantial: it is after all unclear how an emotion can count as a reaction to a value which is neither conceptually represented nor phenomenally 
accessed. It might be that appealing to the fact that an emotion counterfactually depends on the presence of this value - the emotion is elicited if the value is present, not elicited if it is absent-is enough to conclude that the emotion is a reaction to the value. Emotions may sometimes - often, perhaps - manifest this form of counterfactual sensitivity without prior conceptual representation of value or quasiperceptual access to it. ${ }^{22}$

Whether or not this strategy can be worked out, another worry is that the simple model might not be able to do justice to the fact that emotions are responses that are (typically) intelligible from the first-person perspective. The deflationary approach to pre-emotional value representation characteristic of the simple view cannot, it is claimed, deliver on this score (Mitchell, 2021). The intelligibility at stake would consist in the subject's understanding that his anger, say, is a response to what he takes to be offensive. ${ }^{23}$

The first thing to say is that it is far from clear that we should think of first-person intelligibility as a key phenomenon in an account of the emotions. Arguably, the awareness of the relation between a psychological response and what it responds to is absent in creatures that do have emotions, yet are not capable of this perspective taking on their own mental lives. Be that as it may. First-person intelligibility surely exists for creatures like us, and we should try to accommodate it. Initially, it seems that the simple model is at a disadvantage here, since the other models portray emotions as reacting to value representations that are typically first-personal. We obviously cannot do justice to this complex question here, but let us close our discussion with a few words explaining why the issue is not that clear-cut.

First, being aware of a value is often insufficient to account for first-person intelligibility. Perhaps you react with anger, perhaps this is a reaction to your awareness of the offensive, but your response will still not be intelligible unless you have some idea why you represent the relevant situation as offensive. A response as to why you do so will likely make reference to those constellations of natural properties around which the simple model is built: the remark is offensive because it alludes to some unsavory event of your past, say. ${ }^{24}$ Second, if this is along the right track, the

\footnotetext{
${ }^{22}$ There may be different explanations as to the presence of this counterfactual sensitivity (e.g., the "wiring" may be innate, result from a process of acculturation or habit formation). For attempts at implementing this idea, see Echeverri (2019), Deonna and Teroni (2012, 2022).

${ }^{23}$ Observe that this way of cashing out the intelligibility at stake-i.e., as a form of extrinsic intelligibility relating an emotion to a pre-emotional source of evaluative information-is characteristic of the form of attitudinalism that interests us. As we observed above (ftn 16), Mitchell advocates an approach to the emotions according to which they both represent the relevant values and respond to them. This sophisticated approach allows him to speak of a form of intrinsic intelligibility that is not relevant for the worry at issue here.

${ }^{24}$ Many advocates of the idea that value representation is required for intelligibility refer to situations where the subject is allegedly aware of the value and of his emotional response without being aware of the relevant constellation of natural properties (e.g., Poellner 2016). Doesn't that show that it is wrong to insist on the relation between intelligibility and awareness of natural properties? We don't think so and would insist that these situations lack a distinctive kind of intelligibility. If one is aware of offense and anger, yet unaware as to why the situation is offensive, it is far from clear that one has attained the kind of first-person intelligibility at issue. For a nuanced discussion of such situations that insists on the importance of awareness of both natural and value properties for emotional intelligibility, see Michell (2021, pp 61--65).
} 
friend of the simple model may wonder as to the need for a more substantial kind of pre-emotional value awareness in addition to the awareness of the relevant natural properties. The answer is, presumably, that such additional awareness provides the needed understanding of what different types of situations have in common-grasping a situation under the guise of the offensive is grasping what it has in common with situations that may radically differ from it at the natural level. Let us grant this. Still, it is not clear that such an understanding must be deployed prior to the occurrence of all and every emotions. All here depends on whether the friend of the simple model has a story to tell regarding how we progressively move from particular emotional responses to different constellations of natural properties (all constituting instances of a value) to acquiring the concept of the value which unites them. This, however, will have to be taken up at another occasion.

\section{Conclusion}

In this paper, we considered whether the representationalist and the attitudinalist are on a par regarding their capacity to capture the sense in which emotions have evaluative correctness conditions and, more specifically, whether recent attacks against attitudinalism justify abandoning it. Emotional attitudes have a rich profile- they are ways of reacting to representations and engaging with them-and this gives prima facie reason for thinking that they generate evaluative correctness conditions. As we have seen, all depends on whether emotional attitudes manifest the required sensitivity to evidence we see at work in other attitudes such as belief. We have expressed optimism on that count. Finally,weI have assessed whether the psychological underpinnings of this sensitivity to evaluative evidence is such as to threaten the viability of attitudinalism. Here again, we think that there are reasons for optimism: in light of the various models available, the attitudinalist is still clearly in the game.

Acknowledgments We are indebted to Brian Ballard, Justin d'Arms, Roberto Keller, Charlie Kurth, Michael Milona, Jonathan Mitchell, Moritz Müller, Hichem Naar, Michele Ombrato, Edgar Phillips for their comments on previous versions of this paper.

Funding Open access funding provided by University of Geneva.

Open Access This article is licensed under a Creative Commons Attribution 4.0 International License, which permits use, sharing, adaptation, distribution and reproduction in any medium or format, as long as you give appropriate credit to the original author(s) and the source, provide a link to the Creative Commons licence, and indicate if changes were made. The images or other third party material in this article are included in the article's Creative Commons licence, unless indicated otherwise in a credit line to the material. If material is not included in the article's Creative Commons licence and your intended use is not permitted by statutory regulation or exceeds the permitted use, you will need to obtain permission directly from the copyright holder. To view a copy of this licence, visit http://creativecommons.org/licen ses/by/4.0/. 


\section{References}

Ballard, B. S. (2020). The epistemic significance of emotional experience. Emotion Review, 10(10), 1-12.

Ballard, B. S. (2021). Content and the fittingness of emotion. The Philosophical Quarterly.

Barrett, L. F. (2005). Feeling is Perceiving: Core Affect and Conceptualization in the Experience of Emotion. In L. F. Barrett, P. M. Niedenthal, \& P. Winkielman (Eds.), Emotions: Conscious and Unconscious (pp. 255-284). Guilford.

Bengson, J. (2015). The intellectual given. Mind, 124(495), 707-760.

Brandt, R. B. (1946). Moral valuation. Ethics, 56(2), 106-121.

Brentano, F. (1889/1969). The Origin of our Knowledge of Right and Wrong. London: Routledge and Kegan Paul.

Broad, C. D. (1930). Five Types of Ethical Theory. Routledge.

Broad, C. D. (1954). Emotion and sentiment. The Journal of Aesthetics and Art Criticism, 13(2), 203-214.

Brady, M. (2013). Emotional Insight. New York: Oxford University Press.

D’Arms, J., \& Jacobson, D. (2000). The moralistic fallacy: On the "Appropriateness" of emotions. Philosophical and Phenomenological Research, 61(1), 65-90.

Deigh, J. (1994). Cognitivism in the theory of emotions. Ethics, 104(4), 824-854.

Deonna, J. and Teroni, F. (2022). Emotions and Evaluative Knowledge. In A. Scarantino (ed.), The Routledge Handbook of Emotion Theory. New York: Routledge (forthcoming).

Deonna, J., \& Teroni, F. (2012). The Emotions: A Philosophical Introduction. Routledge.

Deonna, J., \& Teroni, F. (2015). Emotions as attitudes. Dialectica, 69(3), 293-311.

Deonna, J., \& Teroni, F. (2021). Which attitudes for the fitting attitude of value. Theoria, 87, 1099-1122.

Dokic, J., \& Lemaire, S. (2015). Are emotions evaluative modes? Dialectica, 69(3), 271-292.

Döring, S. A. (2007). Seeing what to do: affective perception and rational motivation. Dialectica, 61(3), 363-394.

Echeverri, S. (2019). Emotional justification. Philosophy and Phenomenological Research, 98(3), 541-566.

Engel, P. (2013). I-Doxastic correctness. Aristotelian Society Supplementary, 87(1), 199-216.

Ewing, A. C. (1947). The Definition of Good. The MacMillan Company.

Feldman, F. (2004). Pleasure and the Good Life. Oxford University Press.

Foot, P. (2001). Natural Goodness. Oxford University Press.

Frijda, N. (2007). The Laws of Emotion. Lawrence Erlbaum.

Harman, G. (1990). The Intrinsic Quality of Experience. In J. E. Tomberlin (ed.), Philosophical Perspectives 4: Action Theory and the Philosophy of Mind (pp. 31-52). Atascadero, Calif.: Ridgeview.

Harrison, E. (2020). The Prospects of Emotional Dogmatism. Philosophical Studies, 1-21.

Hernandez, J. P. (2020). The attitudinal view and the integration of the particular object of emotion. European Journal of Philosophy, 28(2), 478-491.

Huemer, M. (2005). Ethical intuitionism. Palgrave Macmillan.

Husserl, E. (1988). Vorlesungen über Ethik und Wertlehre 1908-1914. Kluwer.

Lambie, J., \& Marcel, A. (2002). Consciousness and the variety of emotion experience: A Theoretical Framework. Psychological Review, 109(2), 219-259.

Langland-Hassan, P. (2015). Imaginative attitudes. Philosophy and Phenomenological Research, 90(3), $665-686$.

Lauria, F. (2017). The guise of the ought-to-be. a deontic view of the intentionality of desire. In J. Deonna and F. Lauria (eds.), The Nature of Desire (pp. 139-164). New York: Oxford University Press.

Massin, O. (2019). Suffering Pains. In D. Bain \& M. Brady (Eds.), Philosophy of Suffering: Metaphysics, Value, and Normativity (pp. 75-99). Routledge.

McHugh, C., \& Way, J. (2016). Fittingness first. Ethics, 126(3), 575-606.

Mikula, G., Scherer, K. R., \& Athenstaedt, U. (1998). The role of injustice in the elicitation of differential emotional reactions. Personality and Social Psychology Bulletin, 24(7), 769-783.

Milona, M. (2016). Taking the perceptual analogy seriously. Ethical Theory and Moral Practice, 19(4), $897-915$.

Mitchell, J. (2019a). Affective representation and affective attitudes. Synthese, 198, 3519-3546

Mitchell, J. (2019b). The attitudinal opacity of emotional experience. Philosophical Quarterly, 70(280), 524-546. 
Mitchell, J. (2019c). Pre-emotional value awareness and the content-priority view. Philosophical Quarterly, 69(277), 771-794.

Mitchell, J. (2021). Emotions as Feelings Towards Values. Oxford University Press.

Moors, A., Ellsworth, P., Scherer, K., \& Frijda, N. (2013). Appraisal theories of emotion: State of the art and future development. Emotion Review, 5(2), 119-124.

Müller, J. M. (2017). How (not) to think of emotions as evaluative attitudes. Dialectica, 71(2), 281-308.

Müller, J. M. (2018). Emotion as position-taking. Philosophia, 46(3), 525-540.

Müller, J. M. (2019). The World-Directedness of Emotional Feeling: On Affect and Intentionality. Palgrave-McMillan.

Mulligan, K. (2007). Intentionality, knowledge and formal objects. Disputatio, 2(23), 205-228.

Mulligan, K. (2010). Emotions and Values. In P. Goldie (Ed.), The Oxford Handbook of Philosophy of Emotion (pp. 475-500). Oxford University Press.

Naar, H. (2020). Emotion: More like action than perception. Erkenntnis, 1-30.

Oddie, G. (2005). Value, reality and desire. Oxford University Press.

Ombrato, M. D. and Phillips, E. (2020). The mind of the hungry agent: hunger, affect and appetite. Topoi, $1-10$.

Prinz, J. J. (2004). Gut reactions. A perceptual theory of emotion. New York: Oxford University Press.

Pelser, A. (2014). Evaluation, evaluative perception, and epistemic justification. In S. Roeser \& C. Todd (Eds.), Emotion and Value (pp. 107-123). Oxford University Press.

Pitcher, G. (1965). Emotion. Mind, 295, 326-346.

Poellner, P. (2016). Phenomenology and the perceptual model of emotion. Proceedings of the Aristotelian Society, 116(3), 261-288.

Price, H. H. (1969). Belief. George Allen and Unwin.

Quinn, W. (1993). Putting Rationality in its Place. In R. Frey and C. Morris (eds.), Value, Welfare, and Morality. Cambridge: Cambridge University Press. pp. 26-50.

Recanati, F. (2007). Perspectival Thought. Oxford University Press.

Roberts, R. (2003). Emotions: An Essay in Aid of Moral Psychology. Cambridge University Press.

Rossi, M. and Tappolet, C. (2019). What kind of evaluative states are emotions? The attitudinal theory vs. the perceptual theory of emotions. Canadian Journal of Philosophy, 49 (4), 544-563.

Scarantino, A. (2014). The motivational theory of emotions. In J. D’Arms \& D. Jacobson (Eds.), Moral Psychology and Human Agency (pp. 156-185). Oxford University Press.

Scheler, M. (1916/1973). Formalism in Ethics and Non-Formal Ethics of Values, trans. Manfred S. Frings and Roger L. Funk (Evanston: Northwestern University Press).

Searle, J. (1983). Intentionality. Cambridge University Press.

Setiya, K. (2012). Knowing right from wrong. Oxford University Press.

Sharadin, N. (2016). Reasons right and wrong. Pacific Philosophical Quarterly, 97, 371-399.

Siegel, S. (2010). The contents of experience. Oxford University Press.

Smith, M. (1994). The moral problem. Blackwell.

Smith, J. (2014). Are emotions embodied evaluative attitudes? Critical Review of Julien A. Deonna and Fabrice Teroni's “The emotions: a philosophical Introduction”. Disputatio, 6(38), 93-106.

Tappolet, C. (2016). Emotions, value, and agency. Oxford University Press.

Tappolet, C. (2022). The emotions. New York: Routledge (forthcoming).

Thomson, J. J. (1997). The right and the good. The Journal of Philosophy, 94(6), 273-298.

Tucker, C. (Ed.). (2013). Seemings and Justification: New Essays on Dogmatism. Oxford University Press.

Wedgwood, R. (2002). The aim of belief. Noûs, 36, 267-297.

Wringe, B. (2014). The contents of perception and the contents of emotion. Noûs, 48(1), 275-297.

Zamuner, E. (2015). Emotions as psychological reactions. Mind \& Language, 30(1), 22-43.

Publisher's Note Springer Nature remains neutral with regard to jurisdictional claims in published maps and institutional affiliations. 